\title{
BMJ Open Social and somatic determinants of underweight, overweight and obesity at 5 years of age: a Norwegian regional cohort study
}

\author{
Hilde Mjell Donkor, ${ }^{1}$ Jacob Holter Grundt, ${ }^{1}$ Pétur Benedikt Júlíusson, ${ }^{2}$ \\ Geir Egil Eide, ${ }^{3,4}$ Jørgen Hurum, ${ }^{1}$ Robert Bjerknes, ${ }^{2}$ Trond Markestad ${ }^{2,5}$
}

To cite: Donkor HM, Grundt JH, Júlíusson $\mathrm{PB}$, et al. Social and somatic determinants of underweight, overweight and obesity at 5 years of age: a Norwegian regional cohort study. BMJ Open 2017;0:e014548. doi:10.1136/ bmjopen-2016-014548

- Prepublication history and additional material for this paper are available online. To view these files please visit the journal online (http://dx.doi. org/10.1136/bmjopen-2016014548).

Received 1 0ctober 2016 Revised 13 June 2017 Accepted 3 July 2017

\section{CrossMark}

${ }^{1}$ Department of Paediatrics, Innlandet Hospital Trust, Lillehammer, Norway

${ }^{2}$ Department of Clinical Science, Faculty of Medicine and Dentistry, University of Bergen, Bergen, Norway

${ }^{3}$ Centre for Clinical Research, Haukeland University Hospital, Bergen, Norway

${ }^{4}$ Department of Global Public Health and Primary Care, University of Bergen, Bergen, Norway

${ }^{5}$ Department of Research, Innlandet Hospital Trust, Lillehammer, Norway

Correspondence to Professor Trond Markestad; trond.markestad@uib.no

\section{ABSTRACT}

Objective To identify associations between the weight groups underweight (UW), overweight (OW) and obesity $(\mathrm{OB})$ at 5 years of age and exposures related to pregnancy, anthropometric measures at birth, sociodemographic factors, and family health, anthropometric measures and habits.

Design Regional cohort study.

Setting Oppland County, Norway.

Methods Pregnancy data were obtained from a prospective perinatal register for children born in the county, and weight and height were measured by midwives at birth and by public health nurses at 5 years. Other information was obtained from questionnaires completed by parents.

Participants 0 1895 eligible children, current weight and height were obtained for all, weight and length at birth and information from parents for 1119 (59\%) and pregnancy register data for $749(40 \%)$ of the children. The significance of potential explanatory variables from descriptive statistics was tested in multinomial logistic regression analysis.

Results The prevalence of UW, OW and OB among participants was $7.8 \%, 10.6 \%$ and $3.5 \%$, respectively. UW was associated with anthropometric measures at birth and those of parents, but not with sociodemographic or behavioural characteristics. $\mathrm{OW}$ and $\mathrm{OB}$ were associated with anthropometric measures of parents and siblings and with a variety of unfavourable social characteristics, lack of prolonged breast feeding, sedentary behaviour and dental caries, but not with current dietary habits. After adjustments, $\mathrm{OW}$ and $\mathrm{OB}$ were marginally related to birth parameters and diet and unrelated to physical activity, but significantly related to parental body mass index, low parental education and maternal smoking.

Conclusion The strong associations between sociodemographic and behavioural factors and $\mathrm{OW}$ and $\mathrm{OB}$, but not with UW, may suggest that environmental factors are major contributing causes of OW and particularly $\mathrm{OB}$ at 5 years. These results may be helpful in targeting preventive measures against $\mathrm{OW}$ and $\mathrm{OB}$.

\section{INTRODUCTION}

The prevalence of overweight and obesity (OWOB) has increased throughout the world
Strengths and limitations of this study

- Height and weight were measured by health professionals and current measurements were obtained for all the eligible children.

- Information on the families' social characteristics, health, behaviour and habits was extensive.

- Overweight and obesity, but not underweight, were associated with sociodemographic and behavioural factors, suggesting that early childhood intervention aimed at environmental factors may be effective.

- Selection bias cannot be excluded since information other than current weight and height was missing for $41 \%$ of the children.

during the last decades and represents a major health problem. ${ }^{1}$ Obesity in the paediatric population is particularly worrisome since obese children are at high risk of remaining obese as adults ${ }^{3}$ and face the somatic, mental and social consequences of the condition. ${ }^{4}$ It is currently estimated that 41 million children under 5 years of age are overweight $(\mathrm{OW})$ or obese $(\mathrm{OB})$ globally $^{5}$ and reported prevalence of OWOB in children aged 6-9years in Europe are $18 \%-57 \%$ for boys and $18 \%-50 \%$ for girls. ${ }^{6}$ In Norway, reported prevalence of OWOB in children aged 2-19years is in the range $15 \%-17 \%$. $^{78}$

Both genetic and environmental factors are considered risk factors for OWOB. ${ }^{9} 10$ Twin studies have shown a strong genetic component, but also effects of environmental factors, and adoption studies and other studies have supported the role of family environment. However, to our knowledge, there is no consensus regarding their relative significance. In Norway, as in other countries, children of divorced parents, ${ }^{11}$ of mothers with low education ${ }^{7}$ and children living in rural areas ${ }^{12}$ were more often OW or $\mathrm{OB}$, implying that environmental factors are 
essential and that behaviour related to such sociodemographic factors needs to be addressed in the attempts to avoid persistent OWOB. For unknown reasons, the rising prevalence of OWOB in young children may have been somewhat curtailed in Norway ${ }^{8}$ and other countries, ${ }^{13}$ suggesting that preventive measures, such as increased attention to diet and physical activity may be effective. ${ }^{8}$ However, strategies need to be targeted due to the large scale of the OWOB epidemic.

Due to the apparent multifactorial causes of OWOB, a broad variety of potentially explanatory variables needs to be included in studies in order to disentangle its complexity and thereby to understand how prevention and early treatment may be addressed more efficiently. Furthermore, the understanding of predictors of childhood OWOB may improve by addressing the significance of potential exposures in societies with different habits and prevalence of OWOB. Underweight (UW) in childhood has rarely been addressed in otherwise healthy children, and studies in Norway indicate that the prevalence of UW during early childhood has not changed in the same manner as OWOB during the last decades. ${ }^{14} 15$ We therefore suggest that UW during early childhood is more related to genetic predisposition than OWOB and that including UW in studies of OWOB may add to the understanding of the OWOB epidemic. The aim of this population-based Norwegian study was to identify social and somatic determinants of UW, OW and $\mathrm{OB}$ at 5-6 years of age from comprehensive data obtained during pregnancy and early childhood.

\section{METHODS}

\section{Participants}

Parents of all children entering school in Oppland County, Norway, in 2007, were invited to participate in the study when bringing their children to the routine school entry health check-up at 5-6 years of age. Information on demographic and social factors, somatic health, behaviour and family habits was collected by means of a parental questionnaire completed at home, and current height and weight, and crown-heel length and weight registered at birth were reported by the public health nurses. For children of families who declined to participate, anonymous information on current age, sex, weight and height was obtained and reported by the public health nurse. For children born in Oppland County, parents were asked for permission to link the data to the Oppland perinatal database. In this database, data on mothers' prepregnancy height and weight, weight at the end of pregnancy, health and habits before and during pregnancy, birth and infant characteristics were recorded prospectively.

In Norway, virtually all families attend the standard follow-up programme for children from birth to school entry in the public child health clinics. In 2007, the population of Oppland County, which is 1 of 20 counties in Norway, was approximately 183000 . The county has 26 municipalities; two of them are cities with 25 000-30000 citizens in each, while the rest are rural municipalities with towns of variable sizes.

The study was approved by the Regional Committee on Medical Research Ethics (REK 1.2006.3491) and the Norwegian Data Protection Official for Research (02-2006 SI). A signed consent was obtained from one of the parents.

Details about measurements and variables used for describing characteristics and evaluated as potential exposures of UW, OW and $\mathrm{OB}$ are presented in online supplementary table 1 .

\section{Measurements}

Birth weight (BW) and crown-heel length were measured by midwives at the time of birth and reported to the public healthcare clinics. Height and weight at 5 years were measured by the public health nurses. Body mass index (BMI) was calculated as weight $/$ height $^{2}\left(\mathrm{~kg} / \mathrm{m}^{2}\right)$. Prepregnancy height and weight were self-reported, and weight at the end of pregnancy was measured in the hospital prior to delivery. Pregnancy weight gain was calculated and classified as appropriate or excessive according to US guidelines from 2009. ${ }^{16}$

Definitions of the weight groups UW, normal weight $(\mathrm{NW})$, OW and $\mathrm{OB}$ were based on the sex-specific and age-specific BMI criteria (iso-BMI) of the International Obesity Task Force ${ }^{17} 18$ for the children and according to the WHO classification for their parents. ${ }^{19} \mathrm{SD}$ scores (SDS) for the children were based on the current Norwegian growth references. ${ }^{20}$ Infants were defined as being born small for gestational age (SGA), appropriate for gestational age or large for gestational age according to sex-specific Norwegian percentiles. ${ }^{21}$

\section{Variables}

The main outcomes were UW, OW and OB at 5 years of age. ${ }^{17}$ Exposure variables were anthropometric measurements at birth and a wide set of information provided by the parents in the questionnaire and data from the pregnancy database. We dichotomised several ordinal variables in order to create variables that allowed for meaningful comparisons between weight groups and avoid excessive skewness.

Frequencies of different meals and consumption of various food and drink items were recorded, and among these we chose to use frequency of consumption of fruits and vegetables as an index of healthy nutrition and of sugar-sweetened beverages and sweets/snacks as an index of unhealthy nutrition. Physical activity was rated by parents in three dimensions, endurance, gross motor skills and level of activity in sports and play, and a combined activity score was computed and dichotomised as below or at/above a score of 6 (high score reflecting low activity). Additionally, physical activity per week was reported as frequency and as hours of being active enough to experience heavy breathing or sweating. Screen time (TV, videogames and so on) was recorded as hours per day. Binary exposure variables in addition to sex were 
(yes/no) premature birth, kindergarten since 2 years of age, antibiotics more than three times, asthma medication, dental caries, exclusive breast feeding for more than 4 months, television in the child's bedroom, living with one caretaker, having siblings, maternal and paternal education beyond high school, mother smoking, parents working full-time or part-time, parents of western origin (Europe and North America) and parents with UW, OW or OB. Place of residence was categorised as urban and rural.

From the Oppland perinatal database, we obtained prepregnancy height and weight, pregnancy weight gain, BW and the following binary variables (yes/no): mother working before pregnancy and smoking in pregnancy.

\section{Statistics}

Descriptive statistics are presented as counts and per cents (\%) for categorical variables and means with SD for continuous variables. Participants and children whose parents declined were compared using Student's t-test and Pearson's $\chi^{2}$ test. Among participants, differences in characteristics between the four weight groups (BMI category: UW, NW, OW and $\mathrm{OB}$ ) were explored using one-way analysis of variance (ANOVA) for continuous and $\chi^{2}$ test for categorical variables. When ANOVA or $\chi^{2}$ test across all weight groups were significant, we performed post hoc pairwise testing, comparing groups to NW children, by Dunnett's t-test (continuous variables) or $\chi^{2}$ test (categorical variables).

The significance of potential explanatory variables on outcome in terms of the current weight groups UW, OW and OB relative to NW was first analysed in separate bivariate analyses with the ordinal weight group variable (increasing from UW through NW, OW and $\mathrm{OB})$ at 5 years of age, and thereafter assessed in a multinomial logistic regression analysis with variable-specific reference categories for categorical variables or per unit increase for continuous variables. In developing the regression model, all explanatory variables that in bivariate analyses showed significant relation to BMI category in ANOVA or $\chi^{2}$ test were explored for inclusion and significance in a multinomial regression model. The explanatory variables included in an a priori model were based on earlier literature and strength of association in the post hoc bivariate analyses following the ANOVA and $\chi^{2}$ tests, that is, BMI of the mother and father, crown-heel length SDS and weight SDS at birth, maternal education, single parent and maternal and paternal smoking. To avoid excessive loss of statistical power due to a high number of variables in a limited study sample, we then sequentially tested inclusion of potential explanatory variables one at a time into the model. All variables found significant during this sequential testing were assessed in combination using an all-in backward stepwise selection procedure. In the final model, we tested 38 possibly relevant interactions between the remaining variables. They were selected on the basis of literature and theoretical considerations by the authors. Important variables were tested for different interactions and multicollinearity. Finally, the effects of parental education and parental BMI group (stratified) on child outcome in terms of UW and OWOB versus NW were assessed in two separate logistic regression models based on the variable selection in our final multinomial model. SPSS Statistics for Windows V.21.0 was used for all analyses. p Values $\leq 0.05$ was considered statistically significant. The BMI SDS were calculated in R V.2.6.0 (The R Foundation for Statistical Computing, Vienna, Austria) using the Norwegian growth references. ${ }^{20}$

\section{RESULTS}

The mean age $(\mathrm{SD})$ of all eligible children $(\mathrm{n}=1895)$ was $5.70(0.49)$ years, and $923(48.7 \%)$ were boys. The mean BMI (SD) was 15.93 (1.97) for the girls and 15.92 (1.71) for the boys $(\mathrm{p}=0.90)$. There were no significant sex differences in prevalence of UW, OW or OB $(p=0.28)$, that is, the respective prevalence for boys and girls were $9.1 \%$ versus $8.5 \%$ for UW, $10.4 \%$ versus $13.1 \%$ for OW and $3.7 \%$ versus $4.2 \%$ for $\mathrm{OB}$. For $2.7 \%$ of the children, one or both parents were of non-Western, mostly Asian, ethnicity.

Of the 1119 families who answered the questionnaires (59\% of eligible families), 31 were excluded from further analyses because data on height, weight or age at 5 years were missing. The participation rate varied from $20 \%$ to $85 \%$ for the various municipalities in the county. The mean BMI did not differ between the participants and those who declined, but the prevalence of OW and OB were slightly lower for the participants (table 1). Pregnancy data were available for 749 of the children. This subgroup did not differ from those without pregnancy data on any of the exposure or outcome variables (data not shown).

In separate bivariate analyses, the ordinal weight group variable (increasing from UW through NW, OW and $\mathrm{OB}$ ) at 5 years of age was positively associated with exposures during foetal and early life, that is weight, BMI and their respective SDS at birth, prepregnancy weight, excessive pregnancy weight gain and smoking during pregnancy and exclusive breast feeding less than 4 months (table $2 a$ ), with unfavourable current child health and habits, that is, increasing rate of dental caries, a combined physical activity score lower than peers and TV in the bedroom (table $2 \mathrm{~b}$ ) and sociodemographic factors and health of the family, that is, increasing prevalence of low parental education, father out of work, parents of non-Western ethnicity, single parenthood, smoking mothers, being an only child and increasing BMI and prevalence of obesity among parents and siblings (table 2c). Increasing weight group was not associated with being a twin, having a chronic disease (prevalence $2.1 \%$, eg, diabetes, heart disease and coeliac disease), hospital admissions, being breast fed or not (overall prevalence 89.3\%, range 81.690.6 between the groups), frequency or extent of physical activity, screen time, teenage mother, pre-eclampsia, 
Table 1 Characteristics of the children who participated and declined

\begin{tabular}{|c|c|c|c|}
\hline Characteristic & Participated $(n=1088)$ & Declined $(n=776)$ & p Value* \\
\hline Age (years), mean (SD) & $5.71(0.44)$ & $5.68(0.57)$ & 0.185 \\
\hline Height (cm), mean (SD) & $116.4(5.8)$ & $116.1(5.7)$ & 0.307 \\
\hline Body mass index $\left(\mathrm{kg} / \mathrm{m}^{2}\right)$, mean (SD) & $15.87(1.71)$ & $16.01(2.02)$ & 0.107 \\
\hline Boys, n (\%) & $526(47.0)$ & 397 (51.2) & 0.075 \\
\hline Underweight $†$ & $85(7.8)$ & $78(10.1)$ & \\
\hline Normal weight $†$ & $850(78.1)$ & $553(71.7)$ & \\
\hline Overweight $†$ & $115(10.6)$ & $104(13.5)$ & \\
\hline Obese† & $38(3.5)$ & $36(4.7)$ & \\
\hline Overweight or obese & $153(14.1)$ & $140(18.2)$ & 0.017 \\
\hline
\end{tabular}

*Students' t- and $\chi^{2}$ tests.

†Based on body mass index. ${ }^{17}$

gestational diabetes, gestational age at birth or mode of delivery (online supplementary table 2 ).

When compared with NW children in separate bivariate analyses, UW at 5 years was significantly associated with lower weight, BMI and being SGA at birth, and lower prepregnancy and current maternal, paternal and sibling BMI, but not with indices of habits related to nutrition, physical activity or sociodemographic factors (table 2a-c). $\mathrm{OW}$ and $\mathrm{OB}$, however, were not significantly associated with weight, length or BMI at birth, or with being born with BW above $4000 \mathrm{~g}$, but with higher prepregnancy BMI and current high maternal, paternal and sibling BMI, pregnancy weight gain above recommended, maternal smoking during pregnancy and current smoking status, limited breast feeding and low parental education. Parents of children with OW and OB reported that their children had a poorer combined physical activity score than their peers, that is, lower endurance, motor skills and physical activity, and the $\mathrm{OW}$ and $\mathrm{OB}$ children were more often living with one caretaker and with parents of non-western ethnicity. OB children more often had TV in the bedroom and dental caries, but according to the parents, they ate sweets as frequently as their NW peers (table 2a-c).

In the multinomial logistic regression model, the only significant interaction was between maternal BMI and BW SDS, and this interaction was included in the final model (table 3). Test for possible multicollinearity revealed a moderately reduced tolerance for BW SDS and birth length SDS (both 0.33), but minimal multicollinearity among other covariates. Overall, deviations from NW (UW, OW and OB) at 5 years were significantly associated with maternal age, education and smoking habits, and maternal and paternal BMI (equally strong), having no siblings, eating fruit 5 days or more often per week and weight and length SDS at birth (table 3). UW was associated with low paternal BMI, low BW SDS and high birth length SDS, OW with low maternal education and smoking, high parental BMI, no siblings, eating fruits 5 days or more often per week and high BW SDS, and OB with low maternal age, high parental BMI, low maternal education and maternal smoking (table 3). The model explained $13 \%$ of the variance (McFadden's pseudo-Rsquared).

Since there was a significant interaction between the associations of maternal BMI and offspring BW SDS and the risk of childhood OWOB, we performed additional multinomial regression analyses with stratification by the interaction variables. In this model, increasing BW was only significantly associated with increasing risk of childhood OW when mothers had NW or were overweight, but not when the mothers were obese, and BW was not associated with risk of childhood obesity. However, increasing maternal BMI was only associated with a risk of OW and OB for children with medium BW SDS, and not with low or high BW SDS (online supplementary table 3).

In the multivariable logistic regression analyses, OWOB was strongly associated with parental OWOB and low education, especially on part of the mother (table 4a). These effects were still strong after adjusting for the somatic and environmental factors in the multinomial model in table 3. For UW children, there were no such associations (table $4 \mathrm{~b}$ ).

\section{DISCUSSION}

The prevalence of $\mathrm{OW}$ and $\mathrm{OB}$ was lower than reported for this age group in many other countries ${ }^{622}$ but similar to a previous report from another part of Norway. ${ }^{7}$ The broad picture from the unadjusted analyses was that high BMI at 5 years of age was related to a wide range of unfavourable sociodemographic and behavioural factors in addition to high parental BMI and marginally to anthropometric measures at birth. However, in the adjusted analyses, OW and OB and OWOB combined, were still closely related to high parental BMI and sociodemographic and 


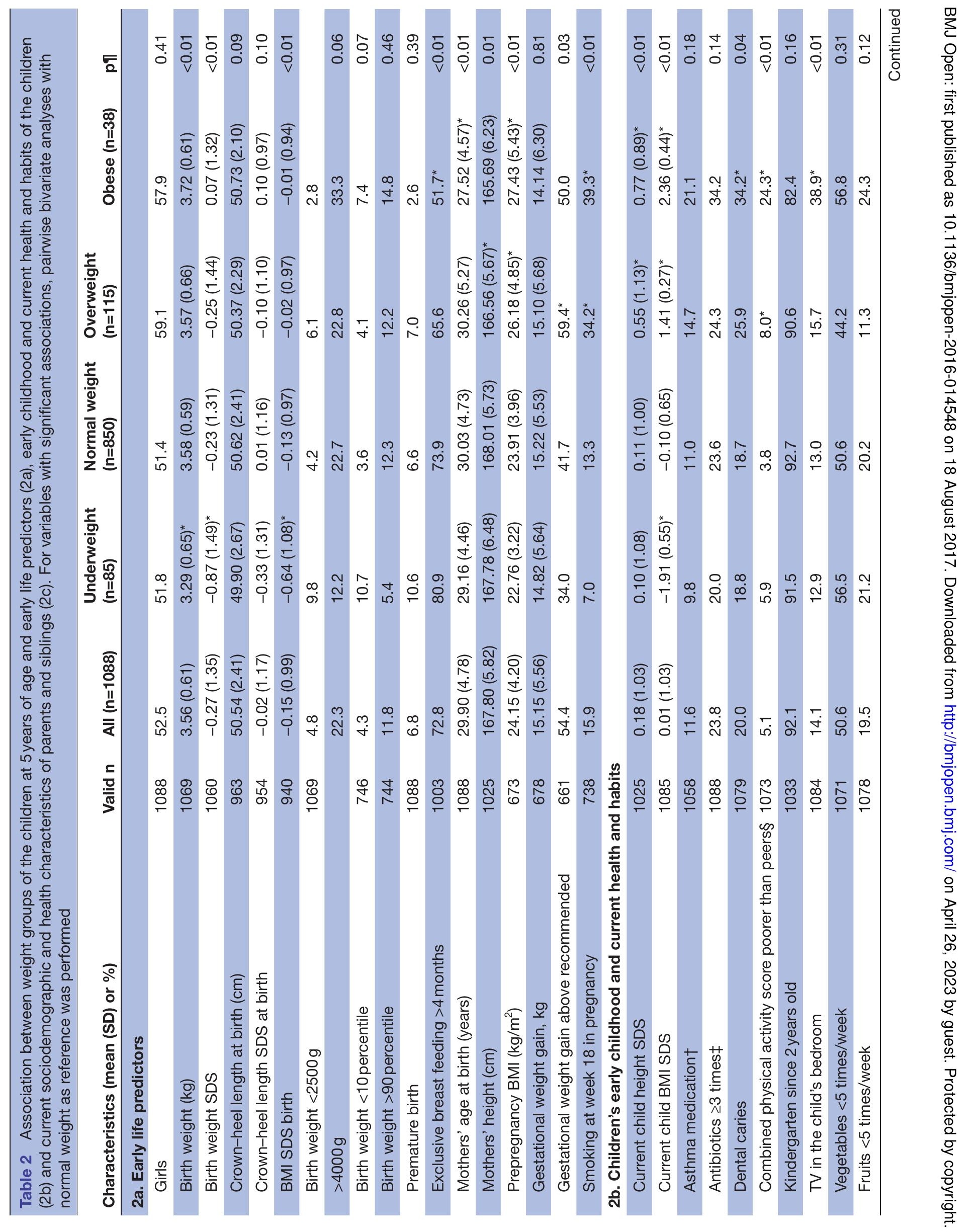




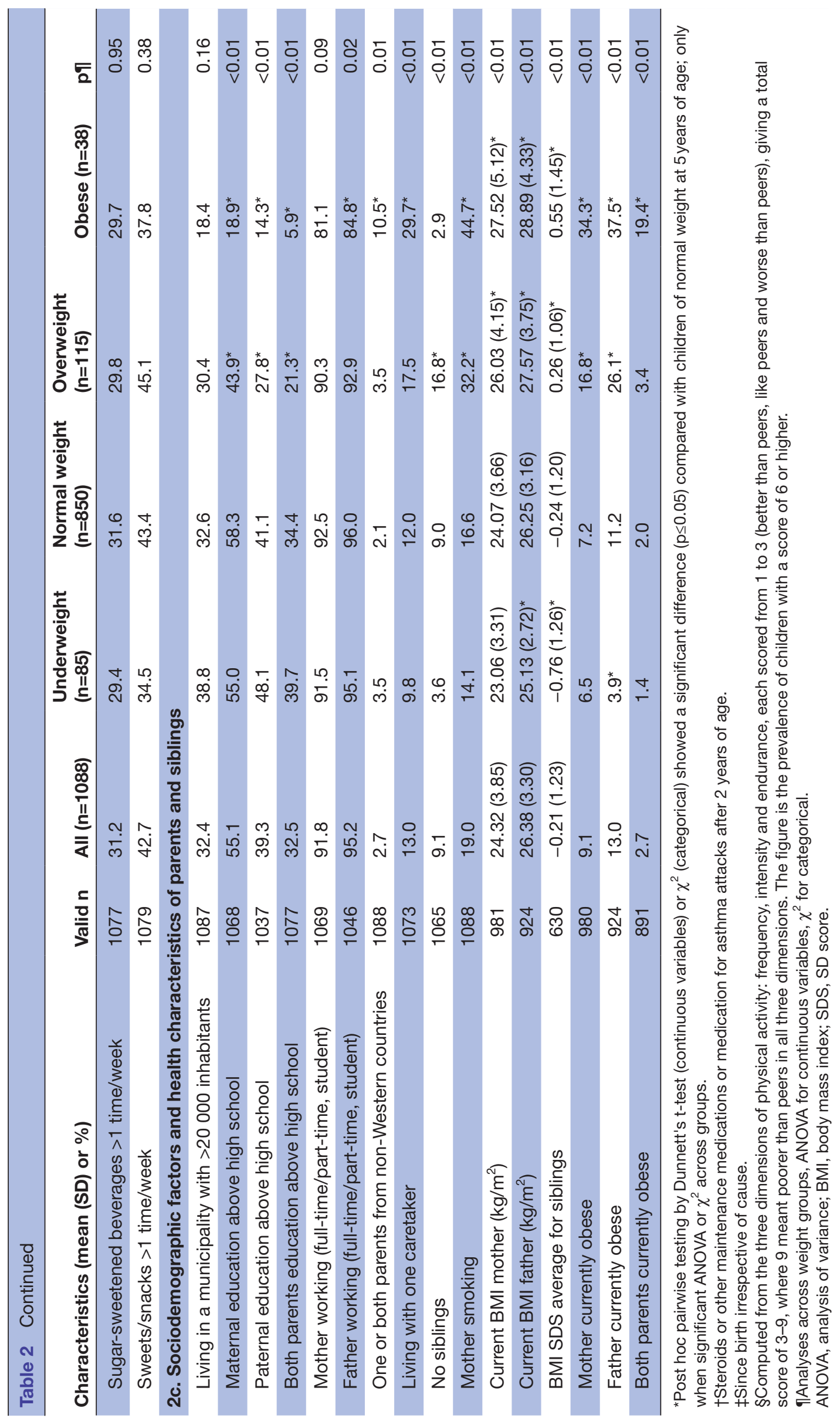




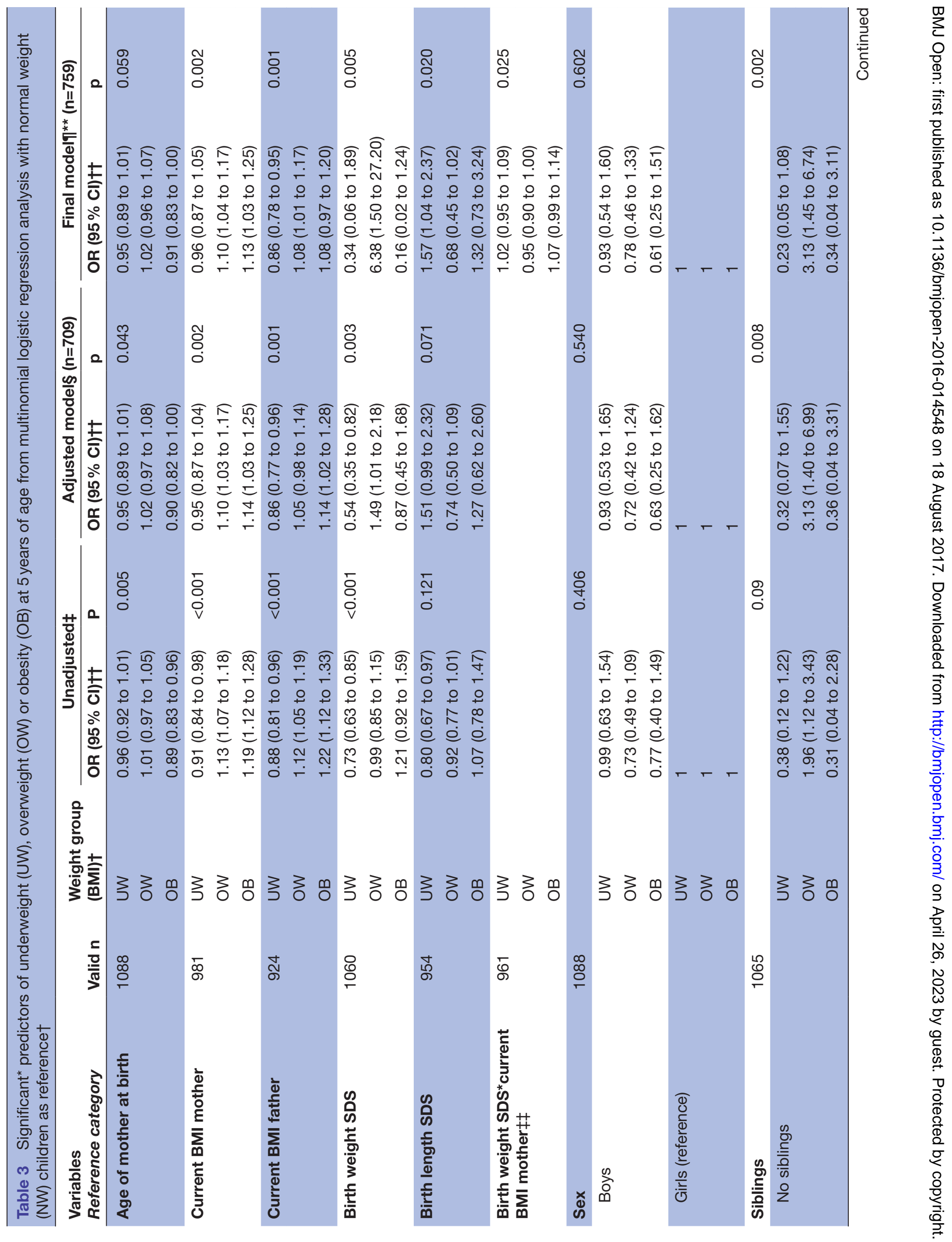




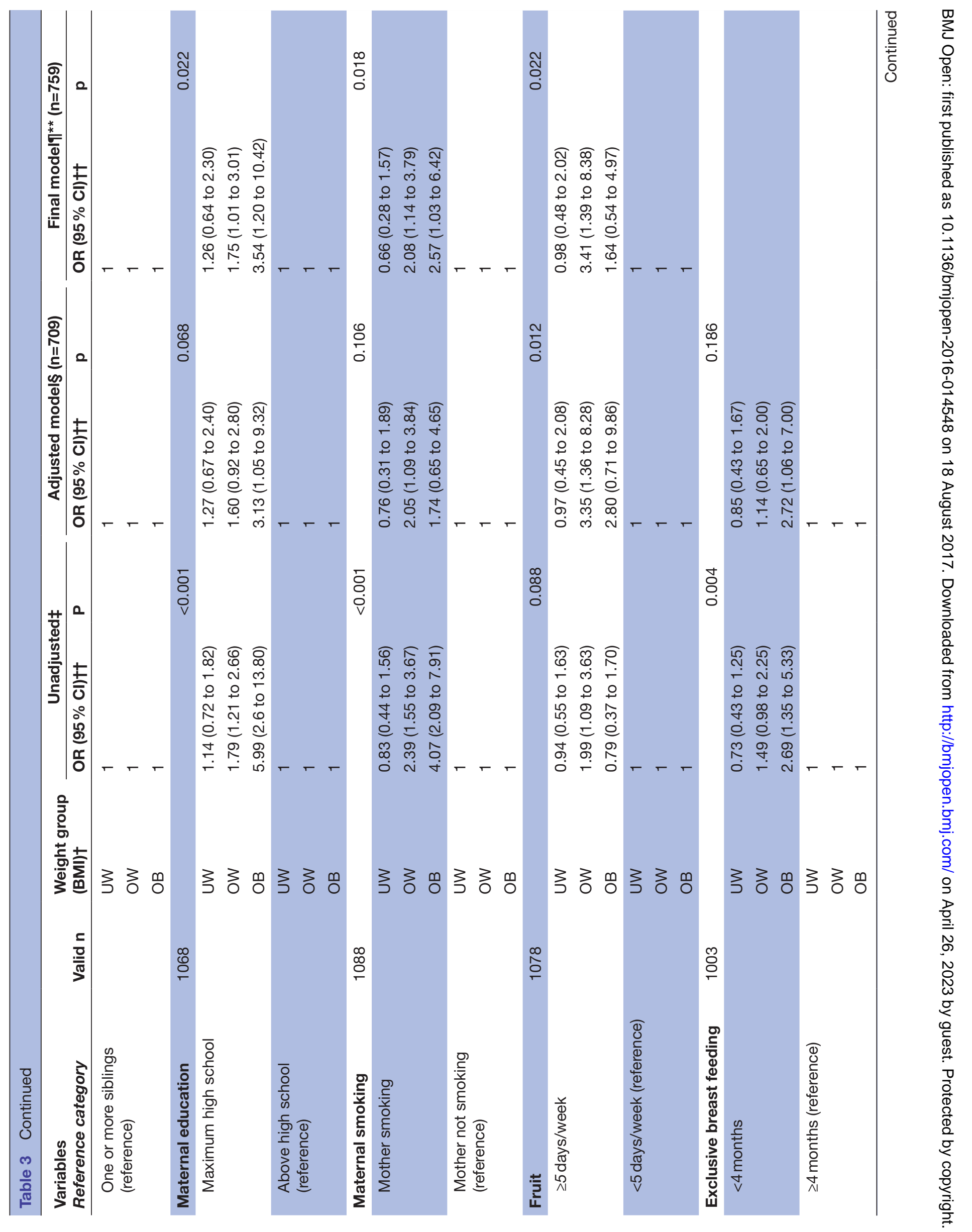




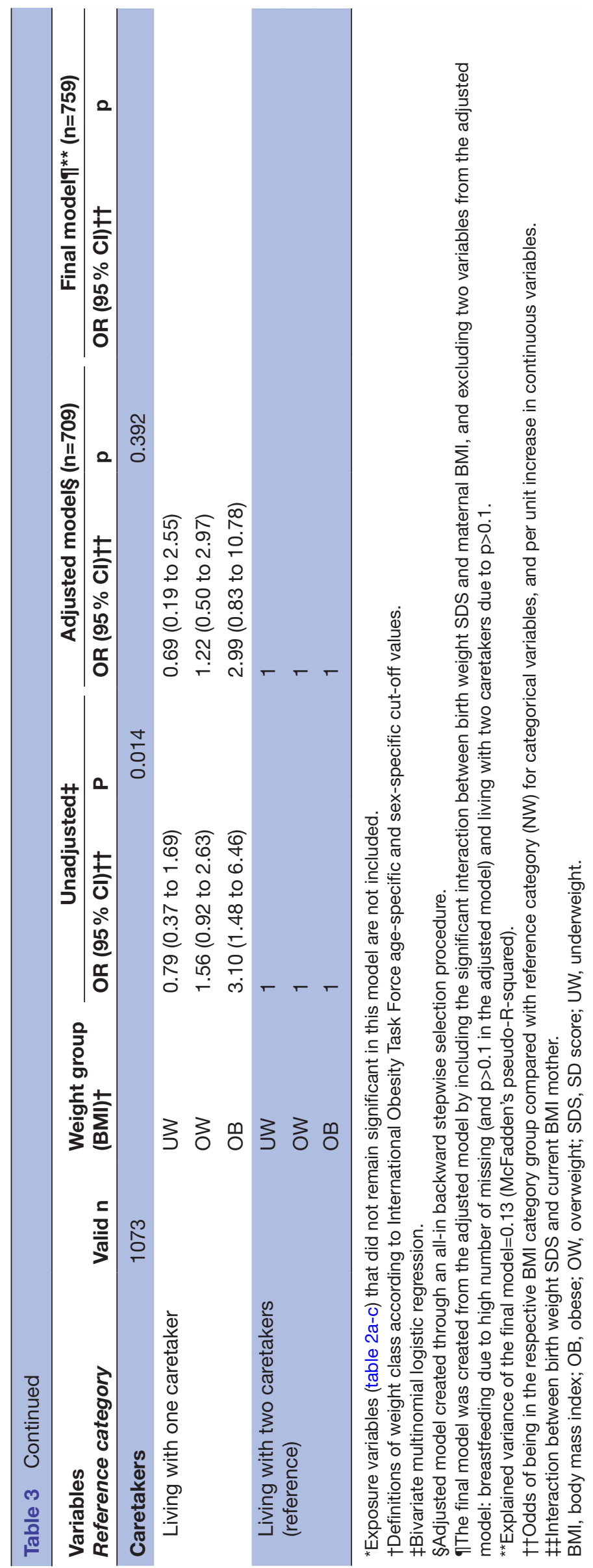


Table 4 Relative risk of overweight or obesity (OWOB, table 4a) and underweight (UW, table 4b) at 5 years of age expressed as ORs and $95 \% \mathrm{Cls}$ according to parental level of education and presence or absence of OWOB or UW. Higher education was defined as one or both parents having education beyond high school

\begin{tabular}{|c|c|c|c|}
\hline & Valid n (total n=963) & $\begin{array}{l}\text { OR (95\% Cl) } \\
\text { Unadjusted }\end{array}$ & $\begin{array}{l}\text { OR }(95 \% \text { Cl) } \\
\text { Adjusted* }^{*}\end{array}$ \\
\hline \multicolumn{4}{|l|}{ 4a. Relative risk of OWOB } \\
\hline Normal weight parents with higher education & 196 & 1 & 1 \\
\hline Normal weight parents with lower education & 87 & $3.6(1.5$ to 8.4$)$ & $3.3(1.3$ to 8.6$)$ \\
\hline OWOB parents with higher education & 416 & $2.4(1.2$ to 5.0$)$ & $2.1(1.0$ to 4.5$)$ \\
\hline \multirow[t]{2}{*}{ OWOB parents with lower education } & 264 & $5.1(2.5$ to 10.3$)$ & $4.6(2.1$ to 9.9$)$ \\
\hline & Valid n (total n=953) & $\begin{array}{l}\text { OR (95\% Cl) } \\
\text { Unadjusted }\end{array}$ & $\begin{array}{l}\text { OR (95\% Cl) } \\
\text { Adjusted* }^{*}\end{array}$ \\
\hline Normal weight mother with higher education & 375 & 1 & 1 \\
\hline Normal weight mother with lower education & 242 & 2.1 (1.3 to 3.4$)$ & $3.0(1.6$ to 5.8$)$ \\
\hline OWOB mother with higher education & 162 & $2.3(1.3$ to 3.9$)$ & $3.4(1.7$ to 6.8$)$ \\
\hline \multirow[t]{2}{*}{ OWOB mother with lower education } & 174 & 5.0 (3.0 to 8.1$)$ & $6.2(3.3$ to 11.7$)$ \\
\hline & Valid $\mathrm{n}$ (total $\mathrm{n}=901$ ) & $\begin{array}{l}\text { OR (95\% Cl) } \\
\text { Unadjusted }\end{array}$ & $\begin{array}{l}\text { OR }(95 \% \mathrm{Cl}) \\
\text { Adjusted }^{*}\end{array}$ \\
\hline Normal weight father with higher education & 144 & 1 & 1 \\
\hline Normal weight father with lower education & 185 & 2.6 (1.5 to 4.5$)$ & 2.6 (1.0 to 6.8$)$ \\
\hline OWOB father with higher education & 223 & $2.8(1.5$ to 5.1$)$ & $1.9(0.7$ to 5.1$)$ \\
\hline OWOB father with lower education & 349 & $6.2(3.6$ to 10.5$)$ & $4.2(1.7$ to 10.2$)$ \\
\hline \multicolumn{4}{|c|}{ 4b. Relative risk of underweight (UW). Since no fathers were UW, only the mothers' data are presented. } \\
\hline & Valid $n$ (total $n=634$ ) & $\begin{array}{l}\text { OR (95\% Cl) } \\
\text { Unadjusted }\end{array}$ & $\begin{array}{l}\text { OR }(95 \% \text { Cl) } \\
\text { Adjusted* }^{*}\end{array}$ \\
\hline Normal weight mother with higher education & 375 & 1 & 1 \\
\hline Normal weight mother with lower education & 242 & $1.4(0.8$ to 2.3$)$ & $1.3(0.6$ to 2.6$)$ \\
\hline UW mother with higher education & 9 & $3.0(0.6$ to 14.8$)$ & $2.4(0.4$ to 13.8$)$ \\
\hline UW mother with lower education & 8 & $\mathrm{n} / \mathrm{a}$ & $\mathrm{n} / \mathrm{a}$ \\
\hline
\end{tabular}

*Adjusted for the variables in the final model in table 3 (sex, maternal smoking, siblings, fruit $>5$ days/week, maternal age, birth weight SDS, birth length SDS) stratified by combinations of parental body mass index and education.

behavioural factors, while OW, but not $\mathrm{OB}$, was positively related to BW. Furthermore, increasing BW was only associated with OW for offspring of mothers who were not obese, while high maternal BMI was only associated with OW and OB for children with normal BW. UW was mainly related to paternal BMI and measurements at birth, but not to sociodemographic or behavioural factors. Thus, as the risks of UW as well as OW and OB were related to parental BMI, genetic factors probably contributed in all groups, but from the overall pattern, we suggest that sociodemographic and behavioural factors were the most important risk factors of $\mathrm{OW}$ and $\mathrm{OB}$ at 5 years and that genetic factors were a relatively more important risk factor of OW than OB. This speculation may be plausible since BMI of OW in early childhood to a significant part may reflect high lean body mass. UW was unrelated to environmental factors, but low parental and child BMI may reflect both genetic heredity and shared environmental factors, and we cannot exclude that rigorous behaviour towards presumed healthy living may have contributed to the risk of UW since our exposure variables were rather crude and based on information on behaviour provided by the parents. Furthermore, the study possibly lacked statistical power to detect effects of environmental factors due to the relatively low number of UW children.

High parental BMI may reflect genetic vulnerability towards OWOB,${ }^{23}$ as well as unfavourable in utero environmental influences ${ }^{162}$ and postnatal maternal and family dietary and other shared habits. ${ }^{25}{ }^{26}$ Such relationships may affect the offspring through foetal programming or developmental plasticity, and this relationship may be signalled, or possibly mediated, by weight and body composition at birth. ${ }^{27}{ }^{28}$ Heavier mothers tend to give birth to heavier babies ${ }^{29}$ and babies with a higher relative fat mass ${ }^{30}$ and studies have shown a positive association between higher BW and OB in later childhood and adulthood. $^{31} 32$ Our finding that anthropometric measures at birth were associated with $\mathrm{OW}$, but not with $\mathrm{OB}$, in the adjusted analyses may indicate that shared environmental factors were relatively more important for the 
development of excess fat mass than lean body mass since OB is usually characterised by higher body fat percentage than OW. ${ }^{33} 34$

Offspring of smoking mothers tend to have lower BW, but they are reported to have a higher risk of later adiposity. ${ }^{35}$ In our study, maternal smoking remained a significant risk factor for $\mathrm{OW}$ and $\mathrm{OB}$ after adjusting for other factors, but whether smoking just reflected other unfavourable family habits or had a direct effect remains speculative. Intrauterine growth restriction has also been associated with risk of adiposity, ${ }^{36}{ }^{37}$ but no such tendency was observed at the age of 5 years in the present study.

We found a cumulative effect of parental BMI and education for the outcome OWOB but not for UW (table 4). The effects on OWOB were present for both parents but were considerably stronger for the mothers than the fathers. This may suggest a more profound effect of maternal factors, possibly through genetic factors or fetal programming, or merely reflect the mothers' dominating influence on family habits, at least when the children are young.

Our findings that the prevalence of OWOB did not differ between urban and rural living or between single caretaker and two-parent families in adjusted analyses are in agreement with some, ${ }^{783} 39$ but not with other studies..$^{11} 124041$ The lack of effect of urbanisation may be due to the small size of the cities and their proximity to rural areas or that relevant differences may not occur or take effect until later ${ }^{12}$ when differences in everyday transportation to school and leisure time activities may differ. The non-significant association between living with a single caretaker and risk of OB may be due to lack of statistical power since $87 \%$ of the children lived with two caretakers. It is remarkable that dietary habits were not or only marginally associated with BMI, OW or OB, as positive associations have been found in other Norwegian studies. ${ }^{42-44}$ It is possible that unhealthy diets were under-reported, as suggested for OW children in another study, ${ }^{45}$ but another possibility was reversed causality, that is, that the OWOB children were put on more healthy or energy restricted diets because they were overweight. Reported physical activity did not differ much between the groups. The reason may be that differences in physical activity are small at this young age when spontaneous play is predominant and more organised activity is largely limited to joint activities in kindergarten, which was attended by more than $90 \%$ of the children. Alternatively, the questions related to physical activity may have been too weak and subjective to disclose differences. In the present study, there were also tendencies towards positive relationships between additional socioeconomic and environmental exposures and OWOB, also in the adjusted analyses, like limited breast feeding, use of asthma medications and antibiotics, presence of caries and TV in the child's bedroom. These findings may be of interest as such associations have been reported by others, ${ }^{46-50}$ and the current study may have been too small to detect significant associations. Whether associations with asthma and antibiotics are directly related to the medications, indirectly to the effects of disease or just were markers of harmful family habits or environments, such as household smoking, need to be explored.

The strengths of this study were both the knowledge of weight and height for all eligible children in the county and the extensive information on those who participated. We cannot exclude some selection bias since there were slightly more children with UW, OW and OB in the families who declined participation. However, the difference in growth parameters were small, and limited participation were probably mainly due to variation in willingness of public health nurses to recruit families rather than variation in willingness on part of the families, as suggested by the wide variation in participation rates in different municipalities. Recall bias may have led to underestimation of true effects of certain exposures, and the relatively small numbers of OW and UW, and particularly $\mathrm{OB}$ children, may have resulted in a lack of statistical power to detect additional true risk factors for these categories. Parental weight, height and habits, for example, related to nutrition and physical activity, were based on self-report and may be biased, although it has been shown that self-reported weights and heights are closely related to actual measurements in adults. ${ }^{51}$ In general, it is important to keep in mind that cross-sectional associations in observational studies may not be causal or may result from reverse causality.

\section{CONCLUSION}

Our results suggest that the predictive value of BW and other measures of size at birth may be relatively high for UW, but limited for OW and, in particular, for OB, at 5 years of age and that high parental BMI, particularly when combined with unfavourable family sociodemographic factors, are the dominant inducting risk factors for early childhood OWOB. Prevention is essential in order to curtail the OWOB epidemic, and in our opinion, this study shows that families with these risk factors should be targeted for close intervention early, preferably before or during pregnancy.

Acknowledgements The authors are indebted to Anne Berit K Sundby, RN, and Ragnhild Gunstad, RN, for extensive technical assistance. We are grateful to all the families who participated in this cohort study.

Contributors HMD: planning, statistical analyses, interpretation of results and initial drafting and writing the paper. JHG: planning, participation in collection of data, statistical analyses, interpretation of results and initial drafting and writing the paper. PBJ: planning, presentation, analyses and interpretation of results and writing the paper. GEE: planning of presentation and statistical analyses, interpretation of results and writing of the paper. $\mathrm{JH}$ : conceptualisation and design of the study, collection of data, planning and interpretation of the results. RB: planning, presentation, analyses and interpretation of results and writing the paper. TM: conceptualisation and design of the study, collection of data, presentation and interpretation of results and writing the paper. HMD had primary responsibility for writing and final content. All authors read and approved the final version of the paper.

Funding This study was supported by unrestricted grants from the Innlandet Hospital Trust. The funding source did not play any role in the design and conduct of 
the study; in the collection, management, analysis or interpretation of the data; or in the preparation, review or approval of the manuscript.

Competing interests All authors have completed the ICMJE uniform disclosure form at www.icmje.org/coi_disclosure.pdf and declare: no support from any organisation for the submitted work; no financial relationships with any organisations that might have an interest in the submitted work in the previous 3 years; no other relationships or activities that could appear to have influenced the submitted work.

Patient consent Guardian consent obtained.

Ethics approval Regional Committee on Medical Research Ethics and the Norwegian Data Protection Official for Research.

Provenance and peer review Not commissioned; externally peer reviewed.

Data sharing statement № other data are published or available from the study.

Open Access This is an Open Access article distributed in accordance with the Creative Commons Attribution Non Commercial (CC BY-NC 4.0) license, which permits others to distribute, remix, adapt, build upon this work non-commercially, and license their derivative works on different terms, provided the original work is properly cited and the use is non-commercial. See: http://creativecommons.org/ licenses/by-nc/4.0/

(c) Article author(s) (or their employer(s) unless otherwise stated in the text of the article) 2017. All rights reserved. No commercial use is permitted unless otherwise expressly granted.

\section{REFERENCES}

1. Ng M, Fleming T, Robinson M, et al. Global, regional, and national prevalence of overweight and obesity in children and adults during 1980-2013: a systematic analysis for the global burden of disease study 2013. Lancet 2014;384:766-81.

2. Forouzanfar MH, Alexander L, Anderson HR, et al. Global, regional, and national comparative risk assessment of 79 behavioural, environmental and occupational, and metabolic risks or clusters of risks in 188 countries, 1990-2013: a systematic analysis for the Global Burden of Disease Study 2013. Lancet 2015;386:2287-323.

3. Simmonds M, Burch J, Llewellyn A, et al. The use of measures of obesity in childhood for predicting obesity and the development of obesity-related diseases in adulthood: a systematic review and meta-analysis. Health Technol Assess 2015;19:1-336.

4. Lobstein T, Baur L, Uauy R, et al. IASO International Obesity TaskForce. Obesity in children and young people: a crisis in public health. Obes Rev 2004;5 Suppl 1:4-85.

5. World Health Organization. Obesity and overweight. Fact sheet. http://www.who.int/mediacentre/factsheets/fs311/en/ (accessed 1 ju 2016).

6. Wijnhoven TM, van Raaij JM, Spinelli A, et al. WHO European Childhood Obesity Surveillance Initiative: body mass index and level of overweight among 6-9-year-old children from school year $2007 / 2008$ to school year 2009/2010. BMC Public Health 2014;14:806.

7. Júlíusson PB, Eide GE, Roelants M, et al. Overweight and obesity in Norwegian children: prevalence and socio-demographic risk factors. Acta Paediatr 2010;99:900-5.

8. Norwegian Institute of Public Health. Proportion of overweight and obese children stable in Norway. https://www.fhi.no/en/all-news-byyear/2016/stabil-andel-barn-med-overvekt-og-fedme/ (accessed 1 Jul 2016).

9. Silventoinen K, Rokholm B, Kaprio J, et al. The genetic and environmental influences on childhood obesity: a systematic review of twin and adoption studies. Int J Obes 2010;34:29-40.

10. Davis MM, Gance-Cleveland B, Hassink S, et al. Recommendations for prevention of childhood obesity. Pediatrics 2007;120 Suppl 4:S229-S253.

11. Biehl A, Hovengen R, Grøholt EK, et al. Parental marital status and childhood overweight and obesity in Norway: a nationally representative cross-sectional study. BMJ Open 2014;4:e004502.

12. Biehl A, Hovengen R, Grøholt EK, et al. Adiposity among children in Norway by urbanity and maternal education: a nationally representative study. BMC Public Health 2013;13:842.

13. Rokholm B, Baker JL, Sørensen TI. The levelling off of the obesity epidemic since the year 1999--a review of evidence and perspectives. Obes Rev 2010;11:835-46.

14. Statistics Norway. Underweight and overweight among girls and boys. 17-year old youth - every 10th girl underweight? [Undervekt og overvekt blant jenter og gutter. 17-årige ungdommer - hvert 10. jente undervektig?]. http://www.ssb.no/helse/artikler-og-publikasjoner/_ attachment/100639?_ts=13d35242ca0 (accessed 02 Dec 2017).

15. Júlíusson PB, Roelants M, Eide GE, et al. Overweight and obesity in Norwegian children: secular trends in weight-for-height and skinfolds. Acta Paediatr 2007;96:1333-7.

16. IOM (Institute of Medicine)NRC (National Research Council). Weight Gain during Pregnancy: reexamining the guidelines. Washington, DC: Press TNA, 2009.

17. Cole TJ, Bellizzi MC, Flegal KM, et al. Establishing a standard definition for child overweight and obesity worldwide: international survey. BMJ 2000;320:1240-3.

18. Cole TJ, Flegal KM, Nicholls D, et al. Body mass index cut offs to define thinness in children and adolescents: international survey. BMJ 2007;335:194.

19. World Health Organisation. The International classification of adult underweight, overweight and obesity according to BMI. apps.who. int/bmi/index.jsp?introPage=intro_3.html (accessed 18 Nov 2014).

20. Júlíusson PB, Roelants M, Nordal E, et al. Growth references for 0-19 year-old Norwegian children for length/height, weight, body mass index and head circumference. Ann Hum Biol 2013;40:220-7.

21. Skjaerven R, Gjessing HK, Bakketeig LS. Birthweight by gestational age in Norway. Acta Obstet Gynecol Scand 2000;79:440-9.

22. Cunningham SA, Kramer MR, Narayan KM. Incidence of childhood obesity in the United States. N Engl J Med 2014;370:403-11.

23. Locke AE, Kahali B, Berndt SI, et al. Genetic studies of body mass index yield new insights for obesity biology. Nature 2015;518:197-206.

24. Knudsen VK, Heitmann BL, Halldorsson TI, et al. Maternal dietary glycaemic load during pregnancy and gestational weight gain, birth weight and postpartum weight retention: a study within the Danish National Birth Cohort. Br J Nutr 2013;109:1471-8.

25. Dubois L, Ohm Kyvik K, Girard M, et al. Genetic and environmental contributions to weight, height, and BMI from birth to 19 years of age: an international study of over 12,000 twin pairs. PLoS One 2012; 7:e30153

26. Skidmore PM, Cassidy A, Swaminathan R, et al. An obesogenic postnatal environment is more important than the fetal environment for the development of adult adiposity: a study of female twins. Am J Clin Nutr 2009;90:401-6.

27. Hochberg Z, Feil R, Constancia M, et al. Child health, developmental plasticity, and epigenetic programming. Endocr Rev 2011;32:159-224.

28. Desai M, Jellyman JK, Ross MG. Epigenomics, gestational programming and risk of metabolic syndrome. Int $J$ Obes 2015;39:633-41.

29. Yu Z, Han S, Zhu J, et al. Pre-pregnancy body mass index in relation to infant birth weight and offspring overweight/obesity: a systematic review and meta-analysis. PLoS One 2013;8:e61627.

30. Catalano PM, Ehrenberg HM. The short- and long-term implications of maternal obesity on the mother and her offspring. BJOG 2006;113:1126-33.

31. Kristiansen AL, Bjelland M, Brantsæter AL, et al. Tracking of body size from birth to 7 years of age and factors associated with maintenance of a high body size from birth to 7 years of age--the Norwegian mother and Child Cohort study (MoBa). Public Health Nutr 2015;18:1746-55.

32. Yu ZB, Han SP, Zhu GZ, et al. Birth weight and subsequent risk of obesity: a systematic review and meta-analysis. Obes Rev 2011;12:525-42

33. Taylor RW, Jones IE, Williams SM, et al. Body fat percentages measured by dual-energy X-ray absorptiometry corresponding to recently recommended body mass index cutoffs for overweight and obesity in children and adolescents aged 3-18 y. Am J Clin Nutr 2002;76:1416-21.

34. Kyle UG, Schutz Y, Dupertuis YM, et al. Body composition interpretation. contributions of the fat-free mass index and the body fat mass index. Nutrition 2003;19(7-8):597-604.

35. Rv K, Toschke AM, Koletzko B, et al. Maternal smoking during pregnancy and childhood obesity. Am J Epidemiol 2002;156:954-61.

36. Varvarigou AA. Intrauterine growth restriction as a potential risk factor for disease onset in adulthood. J Pediatr Endocrinol Metab 2010;23:215-24.

37. Meas T, Deghmoun S, Armoogum P, et al. Consequences of being born small for gestational age on body composition: an 8-year follow-up study. J Clin Endocrinol Metab 2008;93:3804-9.

38. Moraeus L, Lissner L, Yngve A, et al. Multi-level influences on childhood obesity in Sweden: societal factors, parental determinants and child's lifestyle. Int J Obes 2012;36:969-76.

39. Santiago S, Zazpe I, Cuervo M, et al. Perinatal and parental determinants of childhood overweight in 6-12 years old children. Nutr Hosp 2012;27:599-605. 
40. Hesketh K, Carlin J, Wake M, et al. Predictors of body mass index change in Australian primary school children. Int $J$ Pediatr Obes 2009;4:45-53.

41. Hawkins SS, Cole TJ, Law C, et al. An ecological systems approach to examining risk factors for early childhood overweight: findings from the UK Millennium Cohort Study. J Epidemiol Community Health 2009;63:147-55.

42. Andersen LF, Lillegaard IT, Øverby N, et al. Overweight and obesity among Norwegian schoolchildren: changes from 1993 to 2000. Scand J Public Health 2005;33:99-106.

43. Grøholt EK, Stigum H, Nordhagen R. Overweight and obesity among adolescents in Norway: cultural and socio-economic differences. $J$ Public Health 2008;30:258-65.

44. Kristiansen $\mathrm{H}$, Júlíusson $\mathrm{PB}$, Eide GE, et al. TV viewing and obesity among Norwegian children: the importance of parental education. Acta Paediatr 2013;102:199-205.

45. Fiorito LM, Ventura AK, Mitchell DC, et al. Girls' dairy intake, energy intake, and weight status. J Am Diet Assoc 2006;106:1851-5.
46. Bailey LC, Forrest CB, Zhang P, et al. Association of antibiotics in infancy with early childhood obesity. JAMA Pediatr 2014;168:1063-9.

47. Adachi-Mejia AM, Longacre MR, Gibson JJ, et al. Children with a TV in their bedroom at higher risk for being overweight. Int $J$ Obes 2007;31:644-51.

48. Yan J, Liu L, Zhu Y, et al. The association between breastfeeding and childhood obesity: a meta-analysis. BMC Public Health 2014;14:1267.

49. Egan KB, Ettinger AS, Bracken MB. Childhood body mass index and subsequent physician-diagnosed asthma: a systematic review and meta-analysis of prospective cohort studies. BMC Pediatr 2013:13:121

50. Li LW, Wong HM, Peng SM, et al. Anthropometric measurements and dental caries in children: a systematic review of longitudinal studies. Adv Nutr 2015;6:52-63.

51. Tang W, Aggarwal A, Moudon AV, et al. Self-reported and measured weights and heights among adults in Seattle and King County. BMC Obes 2016;3:11. 